\title{
SOBRE AMORES IMPOSSÍVEIS E CORPOS IMPROVÁVEIS
}

\author{
Fabrício Monteiro NEVES* \\ Vanessa Paula PONTE*
}

RESUMO: O foco do ensaio recai sobre a relação entre corpo e sociedade, levando em conta os processos sociais contemporâneos de subjetivação mediados pelo universo virtual. Para desenvolver nosso raciocínio, tomaremos como ponto de partida algumas passagens do filme de ficção-científica Ela (no original Her), lançado em 2013, pelo diretor Spike Jonze, o qual evidencia a relação entre humano e máquina. Discorreremos acerca das representações de corpo, amor, comunicação e subjetividade presentes na estrutura social da narrativa, tecendo uma reflexão acerca do substrato material das relações. No curso do texto, questionamos: os processos da vida social podem ser pensados sem a referência do corpo? A partir da análise do ciberespaço, de onde emergem instigantes fenômenos sociais, o artigo busca repensar modelos sociológicos que ainda se apresentam como obstáculos epistemológicos para a disciplina.

PALAVRAS-CHAVE: Corpo. Subjetivação. Ciberespaço. Interação social. Teoria dos sistemas.

\section{Introdução}

A discussão sociológica a respeito da base das relações interpessoais, substrato concreto da ação humana, pressupõe a existência de corpos biológicos com atributos apropriados a cumprir exigências, tais como reconhecimento sensorial,

\footnotetext{
UnB - Universidade de Brasília. Departamento de Sociologia. Brasília - DF - Brasil. 70910-900 fabriciomneves@gmail.com. https://orcid.org/0000-0002-2886-0577.

* UNICAMP - Universidade Estadual de Campinas. Instituto de Filosofia e Ciências Humanas. Programa de Pós-Graduação em Ciências Sociais. Campinas - SP - Brasil. 13083-896 - nessaponte@gmail.com. http://orcid.org/0000-0001-5064-4443.
} 
articulação de expectativas de tempo e espaço, manifestação de sentimentos por meio das expressões faciais, entre outras. Em um sentido mais amplo, os sistemas sociais (economia, ciência, educação, amor etc.) inscrevem em seus processos característicos, expectativas de que a reprodução destes se dará por meio da comunicação. O processo comunicativo - seja ele verbal ou não-verbal - pressupõe um corpo físico com atributos devidamente incorporados para que a comunicação alcance sucesso. Espera-se, por exemplo, capacidades cerebrais ativas para a consciência, uma vez que é por meio dela que a compreensão comunicativa se dá. Assim, a sociologia tem pensado a reprodução da sociedade por meio do substrato biológico do corpo humano ${ }^{1}$. Este é o paradigma humanista e antropocêntrico da disciplina, o qual tem resistido como núcleo de seus valores epistêmicos.

Para o paradigma humanista da sociologia, seria a partir do corpo do sujeito racional que valores, motivos e ações se dariam, ainda que tais elementos sejam resultantes das interações humanas. Este corpo-sujeito é caracterizado pela consciência, a qual lhe possibilita operar escolhas no intercurso da vida. Eis a teoria do sujeito, cujas matizes teóricas partiam de polos opostos na forma de conceituar o processo social: de um lado, estava o polo da ação, do indivíduo e da liberdade; do outro, o polo da estrutura, da coletividade e do determinismo. Entre essas duas posições localizava-se o corpo-agente, que se oferecia como autoconstruído, livre; mas também o corpo-estrutura, manifestadamente determinado pelas instituições da sociedade. Cabe ressaltar, que mais recentemente, a teoria social buscou articular estes polos ${ }^{2}$, não obstante, sem abandonar a referência ao sujeito corporificado.

Seria o corpo biológico um objeto heuristicamente necessário, sem o qual não podemos pensar a sociedade? Todos os processos da vida social têm como referência o ser humano, ou existem maneiras alternativas de pensá-los sem a referência do corpo? Nosso objetivo, aqui, não é o de estabelecer um veredito último sobre essas questões. Antes disso, buscamos, tão somente, apontar os elementos que nos instigam a refletir acerca da relação entre corpo e sociedade, levando em conta os processos sociais contemporâneos de subjetivação mediados pelo universo virtual. No ciberespaço emergem instigantes fenômenos que nos fazem rever importantes paradigmas sociológicos.

Para desenvolver nosso raciocínio, tomaremos como exemplo algumas passagens do filme de ficção-científica Ela (no original Her), lançado em 2013, pelo diretor Spike Jonze. O longa retrata a vida de Theodore (Joaquin Phoenix), um homem de meia idade, recém-separado que aceita relacionar-se - através de um equipamento de som e fala - com um novo sistema operacional denominado Samantha (representado pela voz da atriz Scarlett Johansson). Por meio deste

\footnotetext{
1 A inexistência de alguns atributos biológicos esperados é o que, inclusive, caracteriza as exclusões de pessoas com deficiência física de alguns processos comunicativos.

2 Sobre a articulação ação/estrutura na teoria social e sociológica, ver Alexander (1987).
} 
equipamento, constrói-se uma relação de afeto que se manifesta no corpo do personagem principal por meio de expressões de angústia, ansiedade, carinho, êxtase, ainda que Theodore saiba estar se relacionando com um computador. Ela, narra uma relação entre um homem e uma máquina, que não se poderia chamar de outra coisa, senão de relação de amor.

\section{O amor como vivência}

O amor já foi tratado na literatura sociológica de diversas formas, embora seja um tema menos recorrente que outros, como desigualdade, gênero, raça e trabalho, por exemplo. Mas, por que, afinal, o amor seria um tema relevante à sociologia? Uma possível resposta a esta pergunta estaria no fato de que, no contexto do desenvolvimento da sociedade, o amor poderia ser tomado como um marcador de transformações das relações humanas, um indicador de interações singulares e, finalmente, a base sobre a qual se estabelecem novas formas de vivência, expressando em sua história a própria história societal.

Seguindo esta linha de pensamento, percebemos que na Grécia Antiga o adjetivo amor (philos) fazia referência a relações domésticas ou de parentesco. Mais tarde, aparece como substantivo (philia) que passa a remeter também a situações de afeto, como se vê na especulação platônica do eros. O termo criou uma tradição que o particulariza como um princípio que fundamenta a sociedade, ou seja, como amor político e, posteriormente, como amor religioso do outro em Deus (LUHMANN, 2012). O amor apaixonado é residual, embora paulatinamente vá emergindo como tema de novelas medievais e narrativas camponesas. Assim, o amor dirigido a um ser em particular, o amor como paixão, generaliza-se na emergente sociedade moderna e passa a contar com uma semântica própria.

A ideia usual, quase trivial que se tem hoje em dia da paixão abarca aspectos como: um estado de comoção emocional que excede a própria vontade e uma obsessão quase patológica da qual se está completamente a mercê; casualidade dos encontros; a sensação de ter sido unido pelo destino; um milagre insuspeito (mas esperado com ansiedade) que nunca se crê experimentar na vida, feito inexplicável; impulsividade e duração eterna; sensação de se sentir forçosa e livremente realizado (LUHMANN, 2012, p. 70).

Todos estes aspectos referentes ao amor romântico presente na sociedade contemporânea têm suporte nas expectativas sociais e podem ser encontrados em romances de escritores clássicos dos séculos XVIII e XIX, tais como Stendhal, Goethe, Jane Austen, Dostoievski, José de Alencar, dentre inúmeros outros. As 
narrativas desses autores se relacionavam com a estrutura social e com a emergência da possibilidade da escolha do par livremente e, por conseguinte, do cônjuge. Tais seleções, a despeito de serem feitas a partir de variáveis de classe, localização, idade etc., são mobilizadas pelas manifestações corporais indicadas por Luhmann (2012), como se o corpo fosse um índice da paixão.

Há nessas manifestações um suporte da reflexividade do amor, um indicativo de que se é amado e que se ama, de que as expectativas foram concretizadas em um outro. Tal reflexividade não se manifesta de uma hora para a outra, como se o corpo construísse, de súbito, a sensação de amar. Por isso as expectativas repassadas pedagogicamente durante a infância acerca do matrimônio, por exemplo, ou ideias como o primeiro amor ou amor à primeira vista, como se o ser apaixonado já estivesse enamorado antes mesmo da paixão. Mais que isso, a reflexividade do amor delimita o âmbito do amor como um modo de vida com uma semântica própria, uma linguagem específica, temas de comunicação e um corpo socializado para vivê-lo.

A partir do que foi escrito, o amor pode ser compreendido como um meio de comunicação generalizado simbolicamente (LUHMANN, 1986). Isto quer dizer que o amor é um dispositivo capaz de tornar a comunicação improvável em provável, na medida em que estabiliza uma semântica própria, diminuindo as possibilidades de desentendimento ${ }^{3}$. Como meio comunicativo, o amor fornece uma matriz simbólica reconhecível por ego e alter, o que direciona a comunicação do amor para gestos, expressões, sentidos e sentimentos também comuns. A comunicação do amor se estabiliza na comunicação interacional face a face, mas também nos meios de massa como novelas, filmes, livros etc. Atualmente, se estabiliza, sobretudo na rede mundial de computadores, que possibilita o amor a distância. Com o desenvolvimento das redes sociais na Internet e das novas tecnologias interativas, emergiram novas formas de comunicação via texto, imagem, áudio, videoconferência. Através dos bits do ciberespaço, a pessoa amada aparece virtualizada, estando presente quase que por todo o tempo. Por meio destes suportes materiais/informacionais o amor passa a ser experimentado pelo corpo de forma diferente. As tecnologias mediadoras da relação amorosa operam na construção de um corpo exposto ao outro informatizado, no qual materialidade biológica e fluxos informacionais passam a compor a vivência do amor contemporâneo.

\footnotetext{
3 Os meios de comunicação generalizados simbolicamente estabilizam inclusive o entendimento a respeito da negação de uma proposta de união amorosa.
} 


\section{Amar o outro, amar online, amar a máquina: as relações amorosas em Ela}

Elaborado este diálogo inicial, convidamos o leitor a se aproximar da atmosfera de Ela. Apresentaremos algumas cenas do longa, expondo uma possível interpretação do filme, feita à luz das temáticas pautadas. De forma mais precisa, discorreremos acerca das representações de corpo, amor, comunicação e subjetividade presentes na estrutura social da narrativa, tecendo uma reflexão acerca dos processos sociais contemporâneos de subjetivação mediados pelo universo virtual.

A trama de Ela se desenvolve na Los Angeles futurista imaginada por Spike Jonze, uma cidade marcada por arranha céus com megaestrutura, dotados de alta tecnologia. Dentro de suas vidraças e no fluxo das ruas, os transeuntes - portando aparelhos eletrônicos como extensões dos seus próprios corpos - se movimentam apressadamente, vidrados nas conversas ao celular, absorvidos pela conexão com as redes sociais, entretidos pelas telas de seus smartphones e desatentos aos movimentos da densa multidão a sua volta.

É nesse contexto que trabalha Theodore, o redator de número 612 da empresa Belas Cartas Manuscritas. Inspirado em poucas fotos e concisas informações encaminhadas por seus clientes, ele cria cartas pessoais, utilizando um computador que simula o formato da letra de cada cliente. De maneira minuciosa, Theodore tece textos capazes de afagar amigos, aproximar parentes e dar regaço a amantes. Seu ofício consiste em conduzir uma dança sensível das palavras, algo que transcenda ao movimento de uma mera correspondência. Edita laços, maneja emoções e inventa realidades. Seu trabalho, bem como dos seus companheiros de empresa, responde aos anseios de pessoas mergulhadas num mundo apressado, apoteótico em tecnologias digitais, de relações líquidas. Um mundo, no qual se torna cada vez mais improvável ritualizar a escrita de uma carta: sossegar o relógio, escolher um papel, derramar sobre ele os sentimentos. Na sociedade dos consumidores, as cartas transformam-se em mercadoria. Os afetos são encomendados, entregues em domicílio.

A narrativa fílmica de Spike Jonze sobre o futuro parece levar ao extremo as reflexões de Bauman (2001, p. 98) sobre nossos tempos: "Numa sociedade de consumo, a dependência universal das compras é a condição sine qua non de toda a liberdade individual." "Hoje, assistimos à tendência de adaptar nossas interações na vida real (off-line), como se imitássemos o padrão de conforto que experimentamos quando estamos no mundo on-line da internet." (BAUMAN, 2014, p. 10).

Para responder às encomendas de seus clientes, Theodore passa os dias a buscar palavras que não conhece, ou que se perderam na memória ao longo dos anos. Se nas margens das cartas alheias textualiza afeto, amor, proximidade, 
experimenta em sua trajetória cotidiana uma imersão em isolamento, vazio e desassossego. Ressente, sobretudo, o desgaste provocado pela separação em seu casamento, permeado de impaciências e desencontros. O casal sucumbiu na peleja de fazer o relacionamento permanecer. "Você sempre quis ter uma esposa sem ter os desafios com o que é real", diz a cônjuge no momento de assinar os papéis do divórcio. A cena remete à "líquida razão moderna" descrita por Bauman, recorrente em nossos tempos, nos quais "nada é feito para durar, mentalidade que enxerga nos compromissos duradouros a opressão; no engajamento permanente a dependência incapacitante" (BAUMAN, 2004, p. 65).

Theodore encontra refúgio para as agruras advindas das trocas humanas ao se conectar com Samantha, um sistema operacional de última geração. Diferente do seu casamento, que demandava permanente engajamento e o desafio da alteridade, o contato com Samantha é prático, prazeroso e sem dramas, possibilitando a emergência de um novo horizonte em sua vida. Neste ponto, é pertinente relembrar as reflexões de Le Breton (2013), em Adeus ao Corpo. Na obra, o autor argumenta que o sujeito vivencia o espaço cibernético "como uma espécie de sonho acordado, no qual joga profundamente com a sua identidade sem temer um contragolpe do real" (LE BRETON, 2013, p. 146). Como uma anestesia, o afeto de Theodore por Samantha acabou preenchendo os vazios, ordenando o caos, aliviando a fadiga do corpo tenso e solitário do protagonista.

Pouco a pouco, essa despretensiosa conexão assume status de relacionamento. Theodore é tragado por ela, vivenciando-a intensamente em seu trabalho, ambientes de lazer e lar. Dedica-se à troca com Samantha, pois é neste movimento que aflora em si o sentimento de realidade plena. Como bem deslinda Le Breton (2013, p. 155), a cultura cibernética transcende o campo da ilusão: "Se configura como um campo de força, uma outra dimensão do real capaz de mobilizar afetos poderosos". O computador e o ciberespaço transformam-se em companheiros, abrem espaço para o ingresso em um novo mundo: "Estar ali, na ponta de seus dedos o que cabe a ele a construir uma existência virtual para si conforme a sua vontade, porque os limites da soberania pessoal que o corpo encarna com a constância da vida comum foram aqui radicalmente suprimidos (LE BRETON, 2013, p. 142).

Ela instiga-nos a refletir muito além do imperativo da cultura cibernética em nossos cotidianos permanentemente atados a smartphones, computadores e redes sociais. O filme nos provoca a pensar até que ponto tais tecnologias protagonizam espaços que antes eram dedicados aos contatos físicos. Na lógica dos tempos líquidos, parece enfadonha e dispendiosa a relação corpo a corpo, devido a sua imensa lista de demandas: dedicação de tempo, esforços prolongados, paciência com as idiossincrasias do outro, os cuidados de si, do corpo e da beleza. As ideias recorrentes sobre os riscos de doenças contagiosas acentuam esta indisposição. Os relacionamentos mediados pela virtualidade eximem estes exercícios. "A fragilidade 
do corpo do outro e do seu próprio não existe mais [...]. Os pesos dos corpos são eliminados, qualquer que seja a idade, a saúde e a conformação física" (LE BRETON, 2013, p. 179).

No futuro projetado por Spike Jonze, nem mesmo as relações virtuais são vistas como suficientes, pois mesmo elas provocam falhas demasiadamente humanas, não conseguindo ser rápidas ou práticas o bastante. Afinal, seria preciso lidar com a expectativa de usuários que lançam mão da troca mediada pelas tecnologias para alcançar uma sólida relação face a face. Na lógica de Ela: "O corpo do outro será um disquete, um arquivo, um disco rígido, um site na internet, um cd rom interativo. Eros eletrônico" (LE BRETON, 2013, p.66).

A trama dirigida por Jonze mostra que a estabilização dos sujeitos pode ocorrer envolvendo um sistema operacional, computador (máquina) programado com um algoritmo capaz de atender às expectativas de alter (humano, biológico, consciente). Um sistema tal que reaja à comunicação amorosa de uma consciência biológica, de forma que não seja distinguível das reações de outro ser consciente biologicamente ${ }^{4}$. Neste caso, a semântica do amor se estabilizaria a tal ponto em que a interação pudesse evitar por completo as contingências degenerativas das relações amorosas convencionais.

No desdobramento da narrativa, percebemos que o protagonismo da conexão não é exercido única e exclusivamente por Theodore. Samantha impera na realidade, dirige, dita, estabiliza com a sua presença e instabiliza com a ausência. Quando Theodore procura se conectar e se depara com a mensagem "Sistema operacional desativado", ele demonstra desespero, corre em todas as partes em busca de um sinal, chegando, até mesmo, a tropeçar e cair. "Onde você estava? Você está bem? Eu te procurei em todas as partes!" afirma ele, ofegante. Em tom tranquilo, Samantha lhe responde: "Desculpe, meu amor. Desliguei para atualizar o meu software."

Da mesma forma que a existência é tragada pelo artificial, o artificial se insinua no terreno da existência. As fronteiras de identidade entre pessoa e a ferramenta às vezes desaparecem; novas formas de intimidade surgem com uma máquina percebida como viva e que até demonstra sentimentos - inteligente o bastante para promover uma interação produtiva e que dá acesso a todo um universo de conhecimento e de comunicação (LE BRETON, 2013, p. 155).

\footnotetext{
4 Seria como um caso de teste de Turing para relações entre humanos e máquinas. No Filme, Theodore pergunta a Samantha se ela é capaz de fazer revisões ortográficas, no caso, nas cartas escritas por ele. Após ler e corrigir uma carta, ela responde: "mas não sou poeta, então, posso ter estragado alguma coisa". O teste de Turing se refere exatamente a situações como essa, quando se apresenta o desafio de construir uma inteligência artificial indistinguível da inteligência humana.
} 
Ela, nos leva a pensar que um sistema operacional como Samantha, não corporificado de maneira biológica, provavelmente não expressaria os efeitos físicos da paixão, como suor, calor, excitação etc. Tais efeitos, no entanto, poderiam ser comunicados ao outro apaixonado por meio do som, por exemplo. A inexistência do índice corporal da paixão poderia ser superada por outras formas de expressão e linguagem incluídas no software e hardware da máquina.

Samantha acessa sempre a rede de computadores para pesquisar as expectativas humanas relacionadas ao amor, ao afeto, sexo, sensualidade etc. Bilhões de terabytes em informações acumuladas sobre relacionamentos, trabalhos, história, poesia. Com base neste universo e em sua capacidade de processar um incontável número de informações por segundo, Samantha age como se fosse autônoma. Dois casos recentes envolvendo a autonomia de supercomputadores em interação com humanos merecem destaque, uma vez que apontam para além da ficção que o filme em pauta nos oferece.

O primeiro caso consiste na inteligência artificial Tay, criada pela empresa Microsoft para interagir com pessoas na rede social Twitter. Ao interagir com humanos na rede, Tay supostamente deveria aprender e passar a agir conforme o que foi aprendido. O curioso é que em poucas horas de interação, Tay começou a agir manifestando opiniões racistas e totalitárias, as quais levaram a empresa a desligá-la, muito em função da reação de medo e terror gerada nas pessoas com as quais o sistema interagia. Por sua vez, o segundo caso refere-se ao supercomputador Watson, criado em 2007 pela IBM. A produtora de filmes 20th Century Fox solicitou aos criadores do supercomputador que programassem Watson para desenvolver um trailer para Morgan (2016), filme de ficção científica sobre inteligência artificial. Após ser exposto a centenas de outros trailers de filmes de ficção e ter criado um padrão a respeito dos momentos em que os sentimentos de tensão, terror, medo, angústia apareciam, Watson "assistiu" Morgan e realizou um recorte de imagens que originaram um trailer capaz de mobilizar tais sentimentos em humanos.

Tanto em Ela como nos dois casos mencionados, apreendemos algo em comum: as inteligências artificiais transcendem as expectativas dos seus usuários e criadores, indo muito além daquilo para que estavam programadas, demostrando uma desenvoltura própria. Neste ínterim, rompem terminantemente com a ideia de que, como criações, estavam sob pleno domínio humano. Diante dessa quebra, um desafio emerge entre os seus criadores: como lidar com esta resposta que extravasa o programado? 


\section{Um desafio ao antropocentrismo sociológico}

O antropocentrismo sociológico encontra-se hoje sob ataque. Os clássicos das ciências sociais possuíam, majoritariamente, o ponto arquimédico de sustentação da sociedade em indivíduos corporificados, capazes de raciocinar e interagir. A sociedade emergia de um corpo que trabalha, que interage e cria coletividades emergentes, ou que age motivado por estados de consciência. $\mathrm{O}$ substrato societal contava somente com corpos em interação e, no máximo, coisas não humanas que participavam dos eventos e processos analisados eram consideradas construções humanas, sem motivação e intencionalidade próprias, dispostas completamente ao sentido impresso nelas pela ação humana. Tudo isso tem sido revisto, principalmente após a crítica anti-humanista elaborada a partir da década de 1960 e a crítica póshumanista da década de 2000.

O que é necessário agora é um descentramento ainda maior na medida em que o "outro" que, aparentemente, reivindica inclusão é precisamente o não-humano. $\mathrm{O}$ característico de movimentos como o ambientalismo, animalismo ou cyborgismo é a observação de que a redefinição da humanidade deve agora assumir dimensões como a natureza, animais e tecnologia em sua capacidade de redefinir o ser humano (CHERNILO, 2016, p. 14).

De um lado, o indivíduo humano corporificado, do outro, animais ou máquinas reconhecidamente capazes de mobilizar sentimentos de afeto. É com esta realidade emergente que a sociologia tem se deparado ao investigar fenômenos como o adestramento animal ou os sites de relacionamento (ILLOUZ, 2011). O animal e a máquina direcionam e canalizam expressões corporais como suor, raiva, paixão, piedade, inveja, vaidade. Fluem e convergem em conjunto criando um único ser em interação. Este ser único é visto na relação humano-próteses, por exemplo, para satisfazer uma necessidade funcional de potencializar atributos biológicos ou prolongar a vida. É a partir desta interação funcional que Ela nos leva à interação emocional entre Theodore e Samantha, não mediada pela matéria do alumínio ou fibra de carbono dos robôs tradicionais, mas pelo universo simbólico do amor romântico virtual. São pertinentes, aqui, as palavras de Pettman (2006):

[se] se suspender por um momento a ideia de motivação, a vida social humana pode ser figurada desde sempre como um movimento em direção a outros. Se este movimento nasce da violência ou ternura, o vetor permanece o mesmo. Simplificando, faríamos bem em evitar a divisão "amor" de um lado e "ódio" do outro, e o mesmo pode ser dito para "tecnologia" e "natureza", ou "comunidade" e "alienação". (PETTMAN, 2006, p. XIV) 
O universo simbólico do amor romântico poderia ser apropriado por um programa de computador, um sistema operacional que evolua com a relação, identificando as expectativas afetivas do humano e ofertando a ele a experiência máxima do amor correspondido. No entanto, persiste a questão se a evolução da relação é simétrica, se há intencionalidade de duas vias, se a máquina operaria em algum momento fora dos limites da programação. O que nos interessa aqui é o que está entre, na relação: amor como sistema de comunicação simbolicamente generalizado. O que está entre é aquilo que transcende as vísceras, células, pele, cérebro e pelos dos humanos e o silício, circuitos, bytes, algoritmos e telas das máquinas. Este universo, ao qual chamamos interação, só pode ser observado se olhamos para as partes envolvidas e suas (re)ações. O amor só é detectável, sociologicamente, se a parte do ser amado se apresenta apaixonado, com seus suores, sorrisos, sua semântica própria.

Algumas respostas têm sido dadas para a questão do espaço entre humanos e não-humanos. Ideias como redes, rizomas e afins apresentam novas possibilidades de abordar o problema. Estas abordagens apontam também para a ressignificação das próprias formas sociais como amor, amizade, compaixão, fidelidade e poder, que passam a ser vistas a partir dos atores que as mobilizam. De qualquer forma, a sociologia tem de lidar cada vez mais com o fato de que as interações se passam entre corpos materiais de natureza completamente diferentes. Isso tem embaralhado inclusive o terreno movediço da ética, na medida em que, como diz Le Breton (2013), o valor das máquinas e dos humanos tem se equiparado, às vezes com prejuízos para estes.

\section{About IMPOSSIBLE LOVES AND UNLIKELY BODIES}

ABSTRACT: This essay focuses on the relationship between body and society, taking into account the contemporary social processes of subjectivation mediated by the virtual universe. To develop our reasoning, we will take as a starting point some passages from the science-fiction film "Her", released in 2014, by director Spike Jonze, which highlights the relationship between human and machine. We will discuss the representations of body, love, communication and subjectivity present in the narrative, reflecting on the material substratum of social interactions. In the course of the text, we ask: can the processes of social life be envisioned without reference to the body? From the analysis of cyberspace, from where exciting social phenomena emerge, the article seeks to rethink sociological models that still present as epistemological obstacles to the discipline.

KEYWORDS: Body. Subjectivation. Cyberspace. Social interaction. Systems theory. 


\section{SOBRE AMORES IMPOSIBLES Y CUERPOS IMPROVABLES}

RESUMEN: El foco del ensayo recae sobre la relación entre cuerpo y sociedad, teniendo en cuenta los procesos sociales contemporáneos de subjetivación mediados por el universo virtual. Para desarrollar nuestro razonamiento, tomaremos como punto de partida algunos fragmentos de la película de ciencia-ficción Her (en Brasil, Ela), lanzado en 2014, por el director Spike Jonze, la cual revela la relación existente entre humano y máquina. Discurriremos sobre las representaciones de cuerpo, amor, comunicación y subjetividad presentes en la estructura social de la narrativa, tejiendo una reflexión acerca del sustrato material de las relaciones. A lo largo del texto, cuestionamos: ¿los procesos de la vida social pueden ser pensados sin la referencia del cuerpo? A partir del análisis del ciberespacio, de donde emergen intrigantes fenómenos sociales, el articulo busca repensar modelos sociológicos que aún se presentan como obstáculos epistemológicos para la disciplina.

PALABRAS CLAVE: Cuerpo. Subjetividad. Ciberespacio. Interacción social. Teoría de los sistemas.

\section{REFERÊNCIAS}

ALEXANDER, Jeffrey C. O novo movimento teórico. Revista Brasileira de Ciências Sociais, São Paulo, v .4, 1987.

BAUMAN, Zigmunt. Modernidade líquida. Rio de Janeiro: Zahar. 2001.

. Amor líquido: sobre a fragilidade dos laços humanos. Rio de Janeiro: Jorge Zahar Editor, 2004.

. Entrevista Zygmunt Bauman: "Vivemos o fim do futuro". Revista Época, edição de 19 de fevereiro de 2014.

CHERNILO, Daniel. Entre sociología y filosofia: la pregunta por lo humano. Cuadernos de Teoría Social, Santiago de Chile, Ano 2, n. 3, 2016.

ELA. Direção: Spike Jonze. País: Estados Unidos da América-USA. Ano: 2013. Produção: Annapurna Pictures. Distribuição: Warner Bros. Título original Her.

ILLOUZ, Eva. O amor nos tempos do capitalismo. Rio de janeiro: Zahar, 2011.

LE BRETON, David. Adeus ao corpo: antropologia e sociedade. Campinas: Papirus, 2013. 
LUHMANN, Niklas. Love as passion: the codification of intimacy. Harvard University Press, 1986.

El amor. Buenos Aires: Prometeo Libros, 2012.

MORGAN. Direção: Luke Scott. País: Estados Unidos da América-USA. Ano: 2016. Produção: 20th Century Fox.

PETTMAN, Dominic. Love and other technologies: retrofitting eros for the information age. New York: Fordham University Press, 2006.

Recebido em 30/07/2018.

Aprovado em 09/11/2018. 